\title{
Degradation of Paraquat in Gramoxone Pesticide with Addition of ZnO
}

\author{
Febrina Arfi ${ }^{1 *}$, Safni ${ }^{2}$, Zaimi Abdullah ${ }^{2}$ \\ ${ }^{1}$ Prodi Kimia, UIN Ar-Raniry, Banda Aceh, Indonesia \\ ${ }^{2}$ Laboratorium Analitik Terapan, Univeritas Andalas, Padang, Indonesia \\ *email: arfi2102@gmail.com
}

Received March 09, 2017; Accepted November 01, 2017; Available online November 30, 2017

\begin{abstract}
Paraquat is the most toxic herbicide, the main agricultural crops and plantations that use them are cloves, cocoa, oil palm, rubber, coffee, and pepper. Therefore, it is necessary to study to degrade paraquat compounds by photolysis method with using $\mathrm{ZnO}$. Photolysis is a process of UV irradiation with a wavelength of 200-400 nm. In this study Photolysis method used UV light with $\lambda=365 \mathrm{~nm}$. Degradation of paraquat compound was done with the influence of variation of time without the addition $\mathrm{ZnO}$, the influence of $\mathrm{ZnO}$ additional variations, and the effect of combination between variations of time and optimization of $\mathrm{ZnO}$ addition. The result of the study shows that photolysis degradation product without the addition of $\mathrm{ZnO}$ for 120 minutes has been degraded by $12.56 \%$. While the optimum addition of 0.1 grams $\mathrm{ZnO}$ increased the percentage of degradation which is about $57.64 \%$. This is proved that the addition of $\mathrm{ZnO}$ with photolysis method can degrade more paraquat compounds.
\end{abstract}

Keywords : degradation, herbicides, paraquat, photolysis, $\mathrm{ZnO}$

\section{INTRODUCTION}

In Indonesia, paraquat has been marketed under the brand name Gramoxone by Syngenta Corporate and by different manufacturers sold under different names as well (Dyson, Js. 2002). Paraquat is the most toxic herbicide, the third most widely used herbicide in the world, almost more than 120 countries and used for more than 50 plants. The main crops and plantations that use them are cloves, cocoa, oil palm, rubber, coffee, and pepper. Paraquat chemical name based on IUPAC is 1,1dimethyl-4,4-bipyridinium dichloride. It is a green liquid with a boiling point $175-180{ }^{\circ} \mathrm{C}$ and is easily soluble in water. Paraquat is relatively stable at normal temperature, pressure, and $\mathrm{pH}$, allowing the paraquat to stay longer in the soil.

Therefore, an appropriate handling of the pollutant processing of the herbicide is required. Advanced Oxidation Process (AOP) shows a very interesting development compared to conventional processing that is often inadequate to treat high concentrations of pollutants or toxic pollutants (Toor. A. P, A. Verma, C. K. Jotshi, P. K. Bajpai, 2006). Degradation of pollutant compounds can be done in various ways, among others through the process: Steam Methane Reforming (SMR), thermochemistry, electrolysis, and photolysis. The SMR process requires an expensive cost. The thermochemical process of high temperature heating can be used from nuclear sources for the process of separating pollutants. Afterwards, the electrolysis process is one of the basic methods passing an electric current on water then it will decompose the toxic compounds pollutants. The electrolysis technology used nowadays requires an enormous amount of electricity. This shows that the energy consumed for the electrolysis process compared to the chemical energy produced is not economically balanced. One simple way that can be used for the degradation of these pollutant compounds is through photochemical processes using photocatalysis methods.

Photocatalysis is one of the processes of degradation of substances assisted by the presence of light. When the photocatalyst material is exposed to light, it absorbs the photon energy which causes various chemical reactions. This chemical reaction can degrade toxic compounds. The advantages of this photocatalytic technology are that the process can take place at room temperature so that its energy needs are much lower. Also, photocatalytic requires only very few chemicals and is relatively cheaper.

Metal complexes and semiconductor are known as photocatalyst materials. The $\mathrm{ZnO}$ semiconductor catalyst was tested for its activity as a photocatalyst in the dyestuffs degradation process (J. Zhao and L.wang. 2011). $\mathrm{Zn}$ is a type of transition metal, reacting 
with oxygen at high temperatures in the air to produce oxides in the form of $\mathrm{ZnO}$. This compound is amphoteric, which is soluble in acids and bases. As with other metal oxides such as $\mathrm{TiO} 2, \mathrm{ZnO}$ is also a semiconductor. $\mathrm{ZnO}$ has a band gap of $3.37 \mathrm{eV}$. Electronic properties such as the band gap play an important role for a semiconductor photocatalyst. With this band gap, $\mathrm{ZnO}$ can be used in UV light photolysis.

The $\mathrm{ZnO}$ powders which have been studied extensively over the years. $\mathrm{ZnO}$ compared with $\mathrm{TiO}_{2}$ has larger quantum efficiency. There are many researchers have reported the $\mathrm{ZnO}$ has higher photocatalytic activities than $\mathrm{TiO}_{2}$ in some conditions (F. Xu, P. Zhang, A. et al). Further more, one dimensional $\mathrm{ZnO}$ structures are widely been prepared, which cn easily been filtered out after the photocatalytic process, while there has not been much success $n$ the synthesis of $\mathrm{TiO}_{2}$ (D.L. Jian, p.X. Gao, W.J. Cai, et al).

Given the high level of paraquat toxicity, research was needed to be done to degrade the compound. In this study, paraquat would be degraded by photolysis method with additional $\mathrm{ZnO}$. The degraded paraquat solution was measured uptake with a UV-Vis spectrophotometer to determine the amount of paraquat successfully degraded. This study aimed to provide information on the conditions needed to degrade pesticide paraquat so it could be converted into compounds that are not harmful to the environment.

\section{EXPERIMENTAL SECTION}

In this study was laboratory scale research where the herbicide paraquat used was Gramoxone herbicide with active ingredient 276 g/L (PT Syngenta Indonesia). The result of paraquat degradation was observed by inspecting the change in absorbance obtained after photolysis using a UV-Vis spectrophotometer.

The tools used were UV-Vis Spectrophotometer (S.1000 Secoman, Sarcelles, France), 10W 365nm UV LED (Germicidal CE G13. Base 8FC11004), magnetic stirrers, analytical balance (Kern, ALJ 220-4m), membrane filter (advanced membrane filters, polymers: cellulose mixed esters $0.45 \mu \mathrm{m}, 25 \mathrm{~mm}$ ), heating, erlenmeyer and other glassware. The materials used were compounds in paraquat pesticides Gramoxone with $276 \mathrm{~g}$ active ingredient/L (PT Syngenta
Indonesia), powdered $\mathrm{ZnO}$ catalysts, and distilled water. The method used in this research was photolysis method with the addition of $\mathrm{ZnO}$ catalyst.

Paraquat dichloride solution with a concentration of $276 \mathrm{~g} / \mathrm{L}$ was taken about $1 \mathrm{ml}$ then diluted in a $100 \mathrm{ml}$ measuring flask with distilled water to the marked limit. So, the paraquat solution with the concentration of $2760 \mathrm{mg} / \mathrm{L}$ was obtained. Then, the paraquat solution with $2760 \mathrm{mg} / \mathrm{L}$ concentration was taken about $7.2 \mathrm{ml}$ and diluted in a $100 \mathrm{ml}$ measuring flask with distilled water to the marked limit, so that the paraquat solution with $200 \mathrm{mg} / \mathrm{L}$ concentration was made. Preparation of paraquat with various concentration $2 \mathrm{mg} / \mathrm{L}$; $4 \mathrm{mg} / \mathrm{L} ; 6 \mathrm{mg} / \mathrm{L} ; 8 \mathrm{mg} / \mathrm{L}$; and $10 \mathrm{mg} / \mathrm{L}$ in the $100 \mathrm{ml}$. The five variations in the concentrated solutions were respectively measured by the UV-Vis spectrophotometer at $200-400 \mathrm{~nm}$ wavelength.

Preparation of $20 \mathrm{ml}$ solution with optimum concentration $4 \mathrm{mg} / \mathrm{L}$. The effect of time toward paraquat degradation had been photolysis at various times of 30 minutes; 60 minutes; 90 minutes; and 120 minutes. And degradation process with optimum concentration $4 \mathrm{mg} / \mathrm{L}$ had been photolysis on various $\mathrm{ZnO}$ catalysts of $0.02 \mathrm{~g}, 0.04 \mathrm{~g}, 0.06 \mathrm{~g}$, $0.08 \mathrm{~g}$ and $0.1 \mathrm{~g}$ for $60 \mathrm{~min}$. The $20 \mathrm{ml}$ solution with optimum concentration was fed into the petri dish. The solution had been photolysis at various times of 30 minutes; 60 minutes; 90 minutes; and 120 minutes with additional $\mathrm{ZnO}$ catalyst according to the result of the optimum degradation percentage from the previous experiment. The results of photolysis were filtered by the filter membranes. The respective absorbance spectra of each solution were measured by a UV-Vis spectrophotometer at the optimum wavelength.

\section{RESULTS AND DISCUSSION}

\section{Measurement Absorption Spectrum of Paraquat}

Paraquat absorption spectrum measurements at $2 \mathrm{mg} / \mathrm{L} ; 4 \mathrm{mg} / \mathrm{L} ; 6 \mathrm{mg} / \mathrm{L} ; 8$ $\mathrm{mg} / \mathrm{L}$; and $10 \mathrm{mg} / \mathrm{L}$ in a solvent of distilled water were using UV-Vis spectrophotometer. This UV-Vis spectrophotometer was an analysis method based on the measurement of monochromatic light absorption of a solution lane in visible and ultraviolet rays. Electromagnetic radiation UV-Vis has a wavelength ranging from 200 to $800 \mathrm{~nm}$. 
Adsorption of radiation will cause electron excitation. Atoms or molecules would absorb at wavelength regions whose energy corresponds to the energy difference between the ground state and the excited state of the atom or molecule and were specific to each of the compounds.

For quantitative measurements, the UVVis spectrophotometer method was used to determine the concentration of the solution where the absorption of light by the solution was a function of concentration. At concentration of $2 \mathrm{mg} / \mathrm{L}$, it was obtained absorbance of 0.235 , while at concentration of $4 \mathrm{mg} / \mathrm{L} ; 6 \mathrm{mg} / \mathrm{L} ; 8 \mathrm{mg} / \mathrm{L}$; and $10 \mathrm{mg} / \mathrm{L}$ respectively obtained the absorbance value of $0.454 ; 0.642 ; 0.882$; and 1,120 . Under optimum conditions, a linear relationship can be made directly between the absorption of the solution and the concentration of the solution. The linear relationship between concentration and absorbance is represented in the standard paraquat calibration curve in Figure 2.
The calibration curve of paraquat standard for paraquat range from $2 \mathrm{mg} / \mathrm{L}$ concentration to $10 \mathrm{mg} / \mathrm{L}$ concentration, the solution for standardized regression with the equation of $y=0.1109 x$ was used to determine the concentration of paraquat herbicide. Based on Lambert-Beer's law, molar absorption coefficient $(\varepsilon)$ paraquat absorption spectrum for each solution concentrations, the solution with a concentration of $4 \mathrm{mg} / \mathrm{L}$ had a value above the molar absorption coefficient level of the respective absorption spectra of each other solution. For further research, $4 \mathrm{mg} / \mathrm{L}$ paraquat solution had been used as the optimum condition for the solution to be photolysis. In determining the absorption spectra pattern of paraquat solution between $200-800 \mathrm{~nm}$, it was obtained the maximum wavelength data of the solution which was 258 $\mathrm{nm}$. This maximum wavelength determination was used for subsequent measurements of the paraquat absorption spectrum solution.

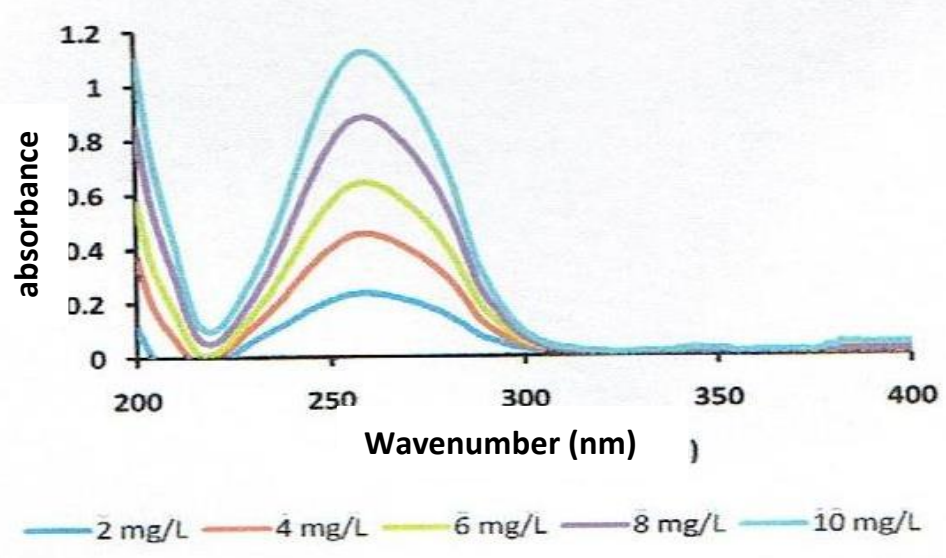

Figure 1. Paraquat absorption spectrum

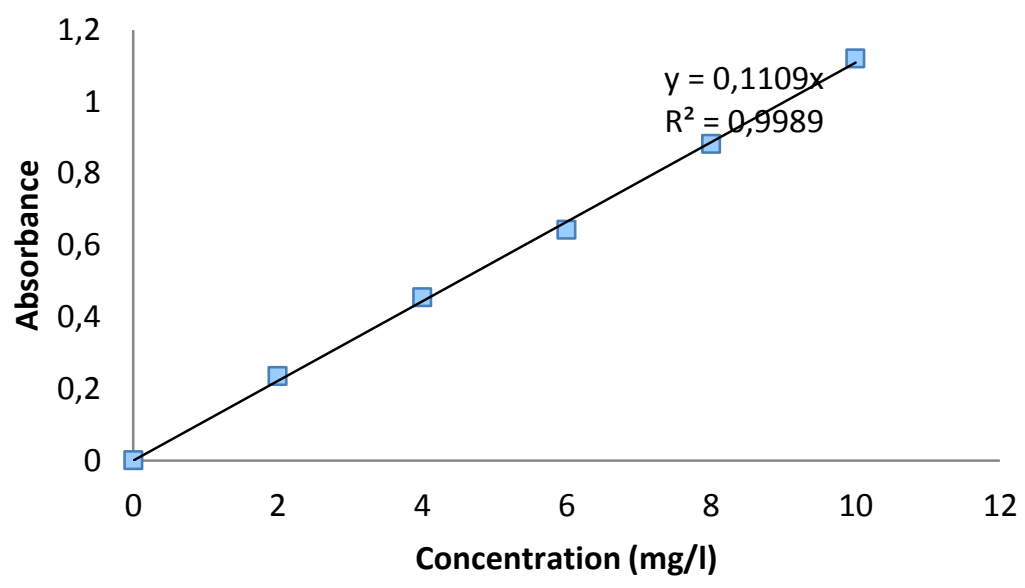

Figure 2. Calibration curve of paraquat standard 
To evaluate the effect of UV irradiation on paraquat degradation was done with some variation of times. The variation of $\mathrm{UV}$ irradiation times were 30 minutes; 60 minutes; 90 minutes; and 120 minutes. Photodegradation of paraquat was performed on a maximum absorption spectrum of $258 \mathrm{~nm}$ with an optimum concentration of $4 \mathrm{mg} / \mathrm{L}$ without the addition of $\mathrm{ZnO}$ catalyst. Figure 3 shows degradation percentage of paraquat with the variation of time.

Degradation percentage at 30 minutes reached $9.69 \%$, while with 60 minutes variation reached $10.03 \%$ and $10,57 \%$ degradation percentage in 90 minutes. While at irradiation of 120 minutes, degradation percent could reach $12.56 \%$. It can be seen that the percentage rate of paraquat degradation was not too large, this indicates that the photolysis of the paraquat might occur even though the percentage of paraquat degradation was not very large. The percentage of paraquat degradation increased with increasing irradiation time, as the longer the irradiation time the greater the amount of $\mathrm{OH}$ radicals that were formed to degrade the paraquat compound.

Paraquat solution with optimum concentration of $4 \mathrm{mg} / \mathrm{L}$ was added by $\mathrm{ZnO}$ catalyst with weight variation of $0.02 \mathrm{~g}$; 0.04 ; $0.06 \mathrm{~g} ; 0.08 \mathrm{~g}$; and $0.10 \mathrm{~g}$. The solution would be photolysis for 60 minutes. During the process of photolysis, there was an ongoing activity of solution stirring with magnetic stirrer. The purpose of this stirring was to equalize the $\mathrm{ZnO}$ particles throughout the paraquat solution portion. The stirring process helped the balance of absorption process on the catalyst surface and helped the process of dissolving oxygen into the suspension. Stirring caused an interaction, when the solution was subjected to the light the reaction that occurs between $\mathrm{ZnO}$ semiconductor photocatalysts and paraquat molecules became more perfect. So it can degrade more paraquat compounds.

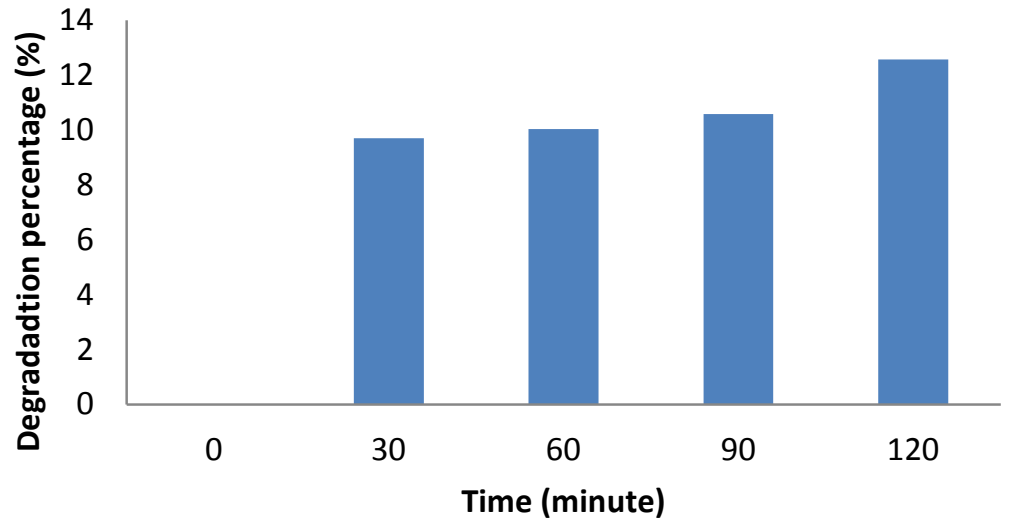

Figure 3. Effect of exposure time photolysis toward percent degradation of paraquat

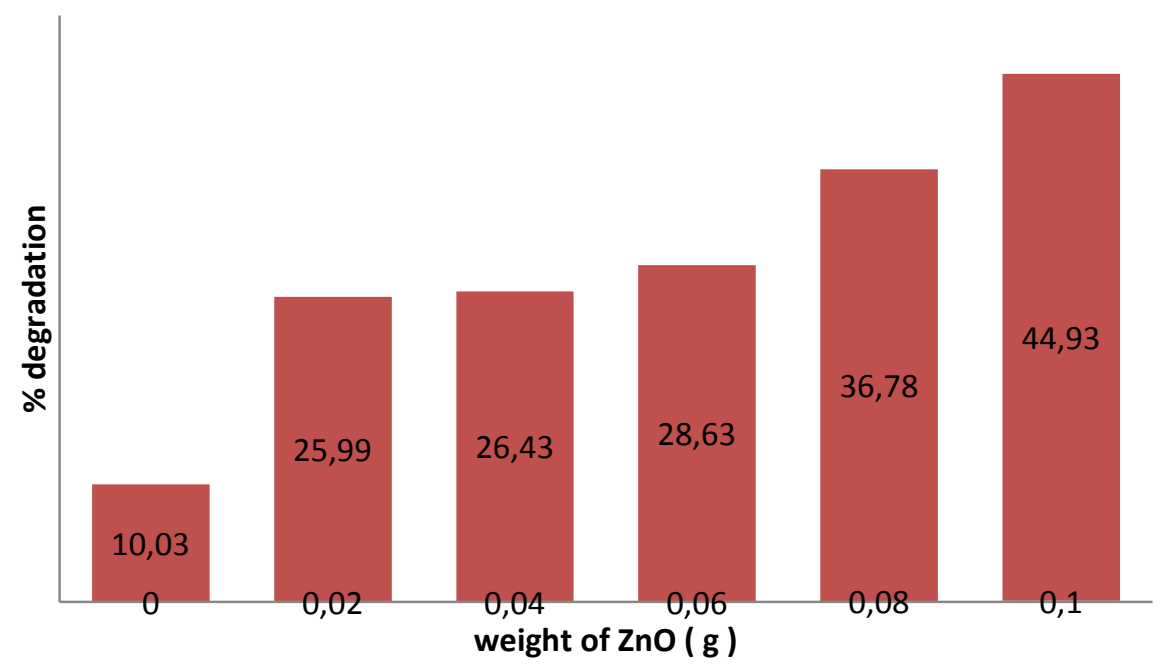

Figure 4. The effect of $\mathrm{ZnO}$ on percent paraquat degradation 
The results of the photolysis of paraquat solution with the addition of $\mathrm{ZnO}$ semiconductor catalyst can be seen in Figure 4. Where this photolysis degradation of paraquat has been added $\mathrm{ZnO}$ catalyst as much as $0.02 \mathrm{~g}$, it could degrade the paraquat by $25.99 \%$, whereas with $\mathrm{ZnO} 0.04 \mathrm{~g}$ catalyst weight degradation became $26.43 \%$. For the addition of $\mathrm{ZnO}$ catalysts of $0.06 \mathrm{~g}$ and $0.08 \mathrm{~g}$ respectively yielded the degradation percentage of $28.63 \%$, and $36.78 \%$.Viewing from the graph, the paraquat degradation increased every additional number of $\mathrm{ZnO}$ catalysts. Although the increment of degradation was not too sharp, for the addition of $0.10 \mathrm{~g}$ catalyst could degrade paraquat almost $50 \%$ which was equal to $44.93 \%$.

Degradation of paraquat using this $\mathrm{ZnO}$ photocatalyst was occurred through the process of paraquat absorption to the surface of catalyst particles simultaneously accompanied by a photocatalytic oxidation (PCO) process against paraquat. When $\mathrm{ZnO}$ was exposed to UV irradiation, in the photocatalyst would occur electron excitation from the valence band to the conductive band which would produce $\mathrm{e}^{-}$, and caused vacancies or holes $\left(\mathrm{h}_{\mathrm{pv}}^{+}\right)$. Positive hole $\left(\mathrm{h}_{\mathrm{pv}}^{+}\right)$which would react with hydroxide that formed hydroxyl radical which is a strong oxidizing agent to oxidize paraquat. For electrons present on the semiconductor surface would be trapped in the hydroxide and could react with the capture of electrons present in the solution. For example, $\mathrm{H}_{2} \mathrm{O}$ or $\mathrm{O}_{2}$ form a hydroxyl or superoxide radical $\left(\mathrm{O}_{2}{ }^{\bullet}\right)$ that will oxidize paraquat.

The mechanism of semiconductor photocatalysis is as follows:

$$
\begin{array}{ll}
\mathrm{ZnO}+\mathrm{hv} & \mathrm{ZnO}\left(\mathrm{h}_{\mathrm{PV}}^{+}\right)+\mathrm{ZnO}\left(\mathrm{e}_{\mathrm{PK}}^{-}\right) \\
2 \mathrm{e}^{-}+\mathrm{O}_{2} & \mathrm{O}_{2}^{-} \\
\mathrm{O}_{2}^{-}+2 \mathrm{H}^{+} & \mathrm{H}_{2} \mathrm{O}_{2} \\
\mathrm{H}_{2} \mathrm{O}_{2}+\mathrm{e}_{\mathrm{PK}}^{-} & \mathrm{HO} \cdot+\mathrm{HO}^{-} \\
\mathrm{h}^{+}{ }_{\mathrm{PV}}^{-}+\mathrm{OH}^{-} & \mathrm{HO} \cdot
\end{array}
$$

Radical (HO•) played a role in degrading chemical compounds. This radical would be formed continuously as long as $\mathrm{ZnO}$ was still subjected to UV rays and attacked the paraquat so it could be degraded more.

Paraquat solution of $4 \mathrm{mg} / \mathrm{L}$ was added with $\mathrm{ZnO}$ semiconductor catalyst as much as $0.10 \mathrm{~g}$. The addition of $0.10 \mathrm{~g}$ catalyst was the optimum result of prior paraquat degradation percentage. Photolysis would then be done with variations of time ie for 30 minutes, 60 minutes, 90 minutes, and 120 minutes. During the course of photolysis, the paraquat solution would be accompanied by stirring. Figure 5 shows that the UV irradiation time of 30 minutes obtained a percentage of paraquat degradation of $38.98 \%$, UV irradiation time of 60 minutes resulted in $44.93 \%$ and UV irradiation for 90 minutes had degradation percent $50.22 \%$. After 120 minutes of percent paraquat degradation, it became $57.70 \%$. With further increase of time, the degradation rate started to increase, and the $\mathrm{ZnO}$ catalysts were completely increased their catalytic activity. The paraquat was easily to absorb on the surface $\mathrm{ZnO}$, thereby speeding up the degradation. Another reason contributing to the enhancement of the photocatalytic activity with the rise of time is that the concentration of hydroxyl ions have more chance to react with the holes to form oxidizing hydroxyl radicals $(\mathrm{OH} \bullet)$.

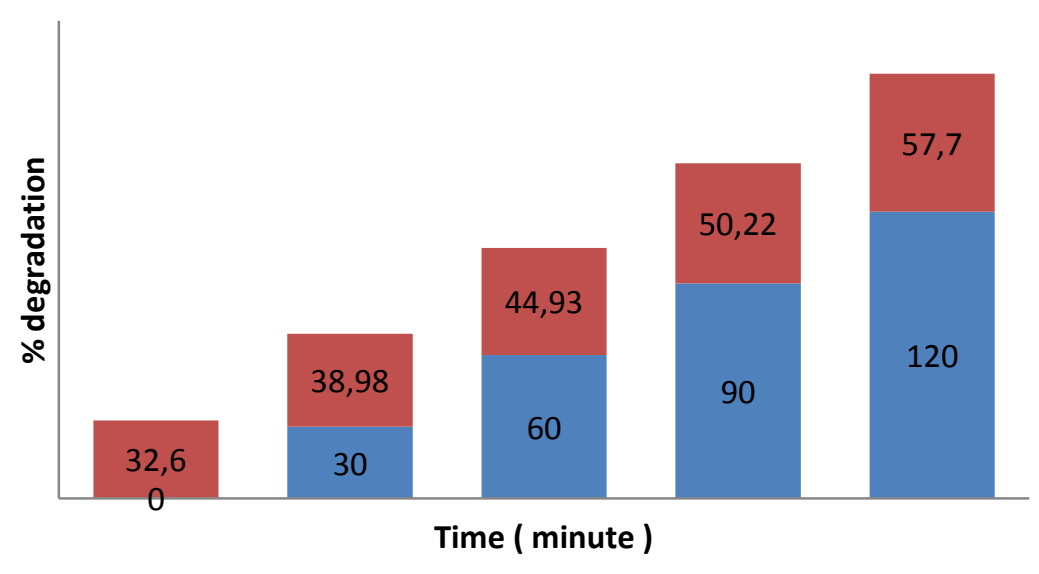

Figure 5. The effect of time toward paraquat percentage degradation. 


\section{CONCLUSION}

Based on the results of research that have been done, it could be concluded that the paraquat degradation obtained by the optimum condition at the concentration of $4 \mathrm{mg} / \mathrm{L}$ with maximum wavelength of the solution was 258 $\mathrm{nm}$. Degradation of $4 \mathrm{mg} / \mathrm{L}$ concentration paraquat solution by photolysis that was irradiation for 120 minutes without addition of $\mathrm{ZnO}$ catalyst could degrade paraquat as much as $12.56 \%$. UV irradiation for 120 minutes with the addition of $0.10 \mathrm{~g} \mathrm{ZnO}$ catalyst (optimum catalyst) paraquat could be degraded by $57.70 \%$. The $\mathrm{ZnO}$ serves as a catalyst that helped to increase the efficiency of photocatalysis the paraquat more faster than without $\mathrm{ZnO}$.

\section{REFERENCES}

Byrappa, K., Subramani, A. K., Ananda, S., Rai, K. M. L., Dinesh, R., \& Yoshimura, M. (2006). Photocatalytic degradation of rhodamine $\mathrm{B}$ dye using hydrothermally synthesized ZnO. Bulletin of Materials Science, 29(5), 433-438. https://doi.org/10.1007/BF02914073

Darajat, S., Aziz, H., dan Alif, A., (2008). Seng Oksida $(\mathrm{ZnO})$ Sebagai Fotokatlis Pada Degradasi Senyawa Metilen Biru. Jurnal Riset Kimia. Hal 179-186. Jurusan kimia UNAND, Padang.

Dyson, J.S. (2002). Environmetal Safety Assesment Of Paraquat Use In Indonesia With Spesial Refferences To Local Study. Syngenta limited. Jealott"s Hill Inernational Centre. Bracknell beckshire RG 2 GEY. UK (Unpublished data).

Hoffmann, M. R., Martin, S. T., Choi, W., \& Bahnemann, D. W. (1995). Environmental Applications of Semiconductor Photocatalysis. Chemical Reviews, 95(1), 69-96. https://doi.org/10.1021/cr00033a004 https://doi.org/10.1021/cm071190g

Jian, D., Gao, P.-X., Cai, W., Allimi, B. S., Pamir Alpay, S., Ding, Y., ... Brooks, C. (2009). Synthesis, characterization, and photocatalytic properties of $\mathrm{ZnO} /(\mathrm{La}, \mathrm{Sr}) \mathrm{CoO} 3$ composite nanorod arrays. Journal of Materials Chemistry, 19(7), 970-975. https://doi.org/10.1039/ B817235H

Ma, H., Williams, P. L., \& Diamond, S. A. (2013). Ecotoxicity of manufactured
$\mathrm{ZnO}$ nanoparticles - A review. Environmental Pollution, 172 (Supplement C), 76-85. https://doi.org/https://doi.org/10.1016/j.e nvpol.2012.08.011

Mai, F. D., Chen, C. C., Chen, J. L., \& Liu, S. C. (2008). Photodegradation of methyl green using visible irradiation in $\mathrm{ZnO}$ suspensions: Determination of the reaction pathway and identification of intermediates by a high-performance liquid chromatography-photodiode array-electrospray ionization-mass spectrometry method. Journal of Chromatography A, 1189(1), 355-365. https://doi.org/https://doi.org/10.1016/j.c hroma.2008.01.027

Oshikiri, M., \& Aryasetiawan, F. (1999). Band gaps and quasiparticle energy calculations on $\mathrm{ZnO}, \mathrm{ZnS}$, and $\mathrm{ZnSe}$ in the zinc-blende structure by the GW approximation. Physical Review $B$, 60(15), 10754-10757. Retrieved from https://link.aps.org/doi/10.1103/PhysRev B.60.10754

Pung, S.Y., Lee, W.P., and Aziz, A., (2012). Kinetic Study of Organic Dye Degradation Using ZnO Particles with Different Morphologies as a Photocatalyst. International Journal of Inorganic Chemistry, vol. 2012. doi:10.1155/2012/608183

Taghi, M. (2014). Humid Acid Degradation By The Synthesized Flower-Like $\mathrm{Ag} / \mathrm{ZnO}$ Nanostrcuturer As An Efficient Phtocatalyst. Journal of Enviromental Health Science and Engineering. 12:138

Vilar, V.J.P., Malato, S., Dionysiou, D.D., (2015). Advanced oxidation technologies: advances and challenges in Iberoamerican countries. Environmental Science and Pollution Research. 759-761. DOI: 10.1007/s11356-014-3160-9

Vora, J. J., Chauhan, S. K., Parmar, K. C., Vasava, S. B., Sharma, S., Bhutadiya, L. S., (2009). Kinetic Study of Application of $\mathrm{ZnO}$ as a Photocatalyst in Heterogeneous Medium. E-Journal of Chemistry. vol. 6, no. 2, pp. 531-536. doi:10.1155/2009/139753

Windarti, I., Muhartono, dan Widayana, I.G.E., (2015). Pengaruh Herbisida Paraquat Diclorida Oral terhadap Derajat 
Kerusakan pada Esofagus Tikus. Jurnal Kedokteran Unila. Vol 5, No 9.

Xu, F., Zhang, P., Navrotsky, A., Yuan, Z.-Y., Ren, T.-Z., Halasa, M., \& Su, B.-L. (2007). Hierarchically Assembled Porous $\mathrm{ZnO}$ Nanoparticles: Synthesis, Surface Energy, and Photocatalytic Activity. Chemistry of Materials, 19(23), 5680-5686.
Zhao, J., \& Wang, L. (2011). Degradation of rhodamine $\mathrm{B}$ in aqueous solution by the $\mathrm{UV} / \mathrm{ZnO}$ photocatalytic process. In 2011 International Conference on Materials for Renewable Energy \& Environment (Vol. 2, pp. 1397-1400). https://doi.org/10.1109/ICMREE.2011.5 930596 